\title{
Never change a winning team : the effect of substitutions on success in football tournaments
}

Citation for published version (APA):

Mengel, F. (2009). Never change a winning team : the effect of substitutions on success in football tournaments. METEOR, Maastricht University School of Business and Economics. METEOR Research Memorandum No. 027 https://doi.org/10.26481/umamet.2009027

Document status and date:

Published: 01/01/2009

DOI:

10.26481/umamet.2009027

Document Version:

Publisher's PDF, also known as Version of record

\section{Please check the document version of this publication:}

- A submitted manuscript is the version of the article upon submission and before peer-review. There can be important differences between the submitted version and the official published version of record.

People interested in the research are advised to contact the author for the final version of the publication, or visit the DOI to the publisher's website.

- The final author version and the galley proof are versions of the publication after peer review.

- The final published version features the final layout of the paper including the volume, issue and page numbers.

Link to publication

\footnotetext{
General rights rights.

- You may freely distribute the URL identifying the publication in the public portal. please follow below link for the End User Agreement:

www.umlib.nl/taverne-license

Take down policy

If you believe that this document breaches copyright please contact us at:

repository@maastrichtuniversity.nl

providing details and we will investigate your claim.
}

Copyright and moral rights for the publications made accessible in the public portal are retained by the authors and/or other copyright owners and it is a condition of accessing publications that users recognise and abide by the legal requirements associated with these

- Users may download and print one copy of any publication from the public portal for the purpose of private study or research.

- You may not further distribute the material or use it for any profit-making activity or commercial gain

If the publication is distributed under the terms of Article $25 \mathrm{fa}$ of the Dutch Copyright Act, indicated by the "Taverne" license above, 


\section{Maastricht University}

Friederike Mengel

Never change a winning team: The effect of substitutions on success in football tournaments

RM/09/027

\section{METEOR}

Faculty of Economics and Business Administration Maastricht Research School of Economics

of Technology and Organization

\section{P.O. Box 616}

NL - 6200 MD Maastricht

The Netherlands 


\title{
Never change a winning team: The effect of substitutions on success in football tournaments.*
}

\author{
Friederike Mengel ${ }^{\dagger}$ \\ Maastricht University
}

June 29, 2009

\begin{abstract}
We identify a strong and significant negative effect of substitutions in (irrelevant) early games in worldcup and olympic football tournaments on performance in later rounds. We argue that this effect is due to the psychological consequences of such a decision and evaluate alternative possible explanations.
\end{abstract}

${ }^{*}$ I thank Ronald Peeters for helpful comments.

${ }^{\dagger}$ Department of Economics (AE1), Maastricht University, PO Box 616, 6200 MD Maastricht, The Netherlands; Tel:+31-43-38 83891; Fax:+31-43-38 84878; E-mail: f.mengel@maastrichtuniversity.nl 


\section{Introduction}

It is widely accepted that even (or especially) in highly professional sports and where a lot of money is at stake, psychological factors can play a huge rule. ${ }^{1}$ One obvious example is psychological pressure to perform well, but there are other factors such as over- or under -confidence, mental focus etc... Furthermore professional sports tournaments provide a good environment to identify such psychological factors, since a) the instutional framework is simple and hence it is easy to understand the incentives facing participants b) incentives are typically very high and c) data are readily available.

In this study we identify a fairly surprising phenomenon, which is the fact that substituting players in irrelevant early games of a tournament has a strong and statistically significant negative impact on further succes in the tournament. We also analyze and discuss possible explanations of this phenomenon.

If a team in a worldcup or olympic tournament has a "good start" it can happen that it is qualified already after two out of three matches for the eliminatory phase. The result of the third game then becomes technically irrelevant for this team, since irrespective of whether it looses or wins this game it will pass on to the next round. Coaches then face the decision of whether to substitute a large amount of their best players in this last game. The reason could be that these players should not waste their efforts in a game whose result doesn't matter or that the reserve players should get the benefit of being able to play at least one game in the tournament.

Analyzing data from previous worldcups and olympic football tournaments, we show that such substitution decisions have a significantly negative impact on the future success of the team in the tournament. We argue that the reasons for this effect are psychological and that furthermore the effect is not (mainly) due to higher psychological pressure (after qualifying early) nor due to a loss of confidence (after performing worse in the last game due to substitutions). Rather we argue that the effect is due to psychological factors such as the loss of mental focus. The study is hence a good example of how psychological effects, which may seem minor a priori, can have a significant impact on outcomes in competitive situations.

There are some other studies of psychological effects on outcomes in sports. Apesteguia and Palacios Huertas (2008) have found that psychological pressure in football tournaments can have a negative effect on performance in penalty shoot-outs. Our results point to aditional psychological factors influencing outcomes. There are of course other studies of the importance of psychological and emotional factors in socio-economic settings. ${ }^{2}$ Typically, though, these effects are hard to document in natural environments. Also somewhat related are Brown et al (2002) who - using partly the same data - have studied the home advantage in worldcup football tournaments. Duggan and Levitt (2002) have related the probability of loosing certain matches among sumo-ringers to corruption. This seems an unlikely cause of our effects, though.

In Section 2 we will describe the data and our research questions. In Section 3 we will present our results, which we discuss in Section 4.

\section{Data and Questions}

We analyze the performance of 168 teams participating in the football worldcups between 19862006, 145 teams participating in the U20 football worldcups between 1997-2008 and 119 teams

\footnotetext{
${ }^{1}$ Studies have found that in media reports about sports competitions psychological factors are referred to more often than other factors, such as talent, prior record, injuries or momentum. See e.g. Edwards and Archambault (1989).

${ }^{2}$ Della Vigna (2007) and Heckmann (2008) provide recent surveys.
} 
participating in the olympic football tournament between 1980-2008. ${ }^{3}$ Data are obtained from the FIFA.com webpage.

All these tournaments start with a group phase in which 4 teams play all against each other, i.e. each team has to play 3 matches. The winner of a game receives 3 points (2 points before 1994) and if a game is tied each team receives one point. The teams with most of the points pass on to the round of last 16 (or directly to the quarterfinal in the case of the olympic tournament). In the round of last 16, 16 teams are matched in pairs and play against each other. The winner of each pair passes on to quarterfinal, winners of the quarterfinal pass on to semifinal etc...

Sometimes a team has such a good start in the tournament, that it is already clear after 2 of their 3 matches that this team will qualify for the round of last 16 (quarterfinal) irrespective of the outcome of the last games in their group. In our data this happened in 74 cases. We will mostly focus on these teams in the analysis and ask the following two questions

1. Are the teams which qualify early for the final rounds more succesful in the remaining tournament than other teams?

2. How does the decision to substitute more or less players in the third (unimportant) match affect the team's success in the remaining tournament?

As we will demonstrate in the following sections, the answer to the first question is "Yes, sometimes" and that to the second question is "negatively". Both effects are strong and statistically significant.

\section{Results}

\subsection{A "good" start in the tournament}

Table 1 illustrates that teams that qualify early $\left(\delta_{Q 2}=1\right)$ have a much higher probability of being succesful also in the Round of last 16, i.e. of reaching the quarterfinal. In fact among the teams that finish first in their group, those that were qualified already after 2 matches pass on to the quarterfinal with probability of $82 \%$ while this probability is only $52 \%$ for all other teams ranked first. This is intuitive since we can expect the teams that qualify early to be "stronger" than those that do not. Note that both probabilities are higher than $50 \%$ since also teams ranked second in the group (and sometimes even third) pass on to the Round of last 16 . Table 1 implies that those are eliminated with higher probability.

\begin{tabular}{|l|l|l|}
\hline Worldcup & $\delta_{Q 2}=1$ & $\delta_{Q 2}=0$ \\
\hline \hline quarterfinal & $\mathbf{0 . 8 2}$ & 0.52 \\
\hline semifinal & 0.50 & 0.53 \\
\hline final & 0.57 & 0.57 \\
\hline
\end{tabular}

(Table 1)

Table 1 also shows that the effect washes out in later stages of the tournament. Conditional on reaching the quarterfinal there are no significant differences anymore in the probabilities of reaching the semifinal or final. (Mann-Whitney, $p>0.8445$ ) The difference between the two groups in the probability of reaching the quarterfinal is significant, though (Mann-Whitney, $p=0.0465$ ).

\footnotetext{
${ }^{3}$ The U20 worldcup takes place every two years and the worldcup only every four years. We also wanted to analyze data from the women's worldcup, but we found that there all teams (except for Russia in 2003) that qualified after 2 games passed on to the semifinals.
} 
In the U20 worldcup things look slightly different as Table 2 illustrates. The difference between both groups is smaller and not signficantly different (Mann-Whitney, $p>0.3222$ ). Having a good start into this tournament hence is not a good predictor of being succesful afterwards (again conditional on finishing first in the group). This seems somewhat surprising, but we will try to shed light on this question in the following subsection.

\begin{tabular}{|l|l|l|}
\hline U20 Worldcup & $\delta_{Q 2}=1$ & $\delta_{Q 2}=0$ \\
\hline \hline quarterfinal & 0.62 & 0.52 \\
\hline semifinal & 0.31 & 0.50 \\
\hline final & 0.25 & 0.60 \\
\hline
\end{tabular}

(Table 2)

Finally in the Olympic tournament differences are even smaller and again not significant (MannWhitney, $p>0.3161$ ). This is illustrated in Table 3. (Remember that in the olympic tournament teams there is no Round of last 16 and teams qualify directly for quarterfinals).

\begin{tabular}{|l|l|l|}
\hline Olympic T. & $\delta_{Q 2}=1$ & $\delta_{Q 2}=0$ \\
\hline semifinal & 0.78 & 0.66 \\
\hline final & 0.45 & 0.66 \\
\hline
\end{tabular}

(Table 3)

\subsection{Substitution decisions}

Next we would like to answer our second question of whether the substitution decision in the third game affects the future success of the team in the tournament. First let us have a look at the distribution of these decisions.

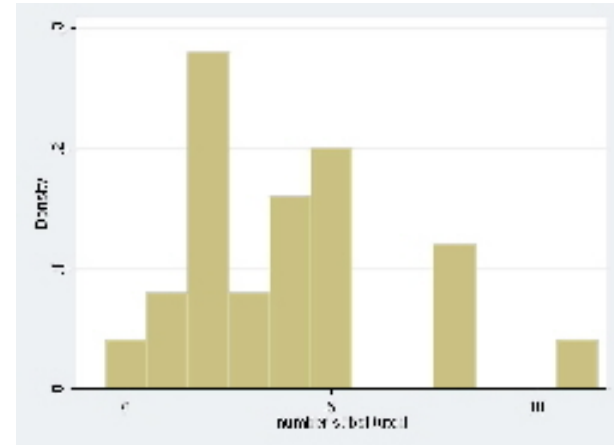

Fig 1: Substitutions Worldcup

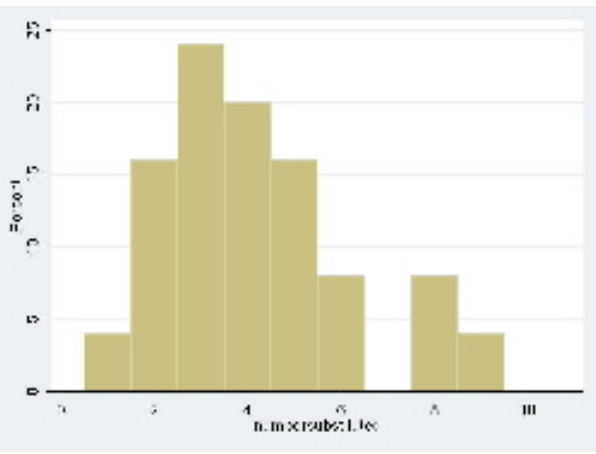

Fig 2: Substitutions U20 Worldcup

Figure 1 shows the distribution of substitution decisions in the Worldcups. On average 3.92 players were substituted in this match with the median number of substitutions being 4 . Most coaches decided to substitute 2 players in this game but sometimes also no players or even all 11 players are substituted. In the U 20 worldcup the average number of substitutions was 4.16 with the median being 4. Most coaches opt for substituting 3 players, the minimum was one substitution and the maximum 9 players. 


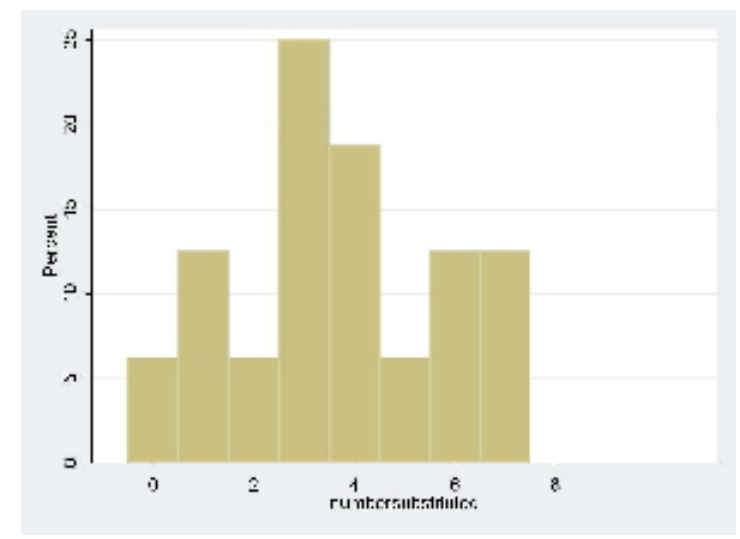

Fig 3: Substitutions Olympic

Tournament

In the Olympic tournament on average 3.69 players were substituted in these games. The median number of substitutions was again 4 . Most coaches opt for substituting 3 players, the minimum was 0 and the maximum 7 substitutions.

Next we will illustrate that substituting more players has a negative effect on the success of the team in later stages of the worldcup. As a first measure we create a variable $\delta_{4}$ which takes the value 1 if at least 4 players were substituted in this game and zero otherwise.

\begin{tabular}{|l|l|l|}
\hline Worldcup & $\delta_{4}=1$ & $\delta_{4}=0$ \\
\hline \hline quarterfinal & $\mathbf{0 . 6 5}$ & $\mathbf{1}$ \\
\hline semifinal & 0.53 & 0.63 \\
\hline final & 0.57 & 0.60 \\
\hline
\end{tabular}

\begin{tabular}{|l|l|l|}
\hline $\mathrm{U} 20$ & $\delta_{4}=1$ & $\delta_{4}=0$ \\
\hline \hline quarterfinal & $\mathbf{0 . 4 2}$ & $\mathbf{0 . 8 9}$ \\
\hline semifinal & 0.33 & 0.5 \\
\hline final & 0.5 & 0.6 \\
\hline
\end{tabular}

(Tables 4+5)

In the worldcup, the disruptive effect for the round of last 16 is strongly significant (Mann-Whitney, $p=0.0206$ ) and insignificant for later rounds (Mann-Whitney, $p>0.4807$ ). For the U20 worldcup the effect is even stronger with those substituting less than 4 players passing on to the quarterfinal with a probability that is more than twice as high as those of all others. The effect is highly significant for the quarterfinal (Mann-Whitney, $p=0.0314$ ) and not significant afterwards (Mann-Whitney, $p>0.3213$ ). For the olympic tournament the effect is marginally significant for the semifinal (MannWhitney, $p=0.0943$ ), but not significant for the final (Mann-Whitney, $p=0.7139$ ).

\begin{tabular}{|l|l|l|}
\hline Olympic & $\delta_{4}=1$ & $\delta_{5}=0$ \\
\hline semifinal & 0.63 & 0.96 \\
\hline final & 0.5 & 0.67 \\
\hline
\end{tabular}

(Table 6)

Furthermore passing probabilities (in the group $\delta_{4}=1$ ) are not significantly different from 0.5. $(p>0.1686)$ in any of the three tournaments, despite the fact that all the teams considered have been highly succesful before the substitution decision.

Figures 4-6 illustrate the probability of reaching the quarterfinal, semifinal, final as a function of the number of players substituted. The points in these graphs are obtained from a logit regression of the probability to reach the quarterfinal $\operatorname{Pr}($ reached8) (or semifinal $(\operatorname{Pr}($ reachedsemi) in case of the olympic tournament) and of the unconditional probabilities to reach all further rounds regressed on the number of players substituted. In all regressions the coefficient on $n$ is significant at least at $5 \%$ for the quarterfinal (semifinal in case of the olympic tournament) and insignificant for the semifinal 
and final. The negative effect of the number of substitutions becomes quite clear from looking at these graphs.

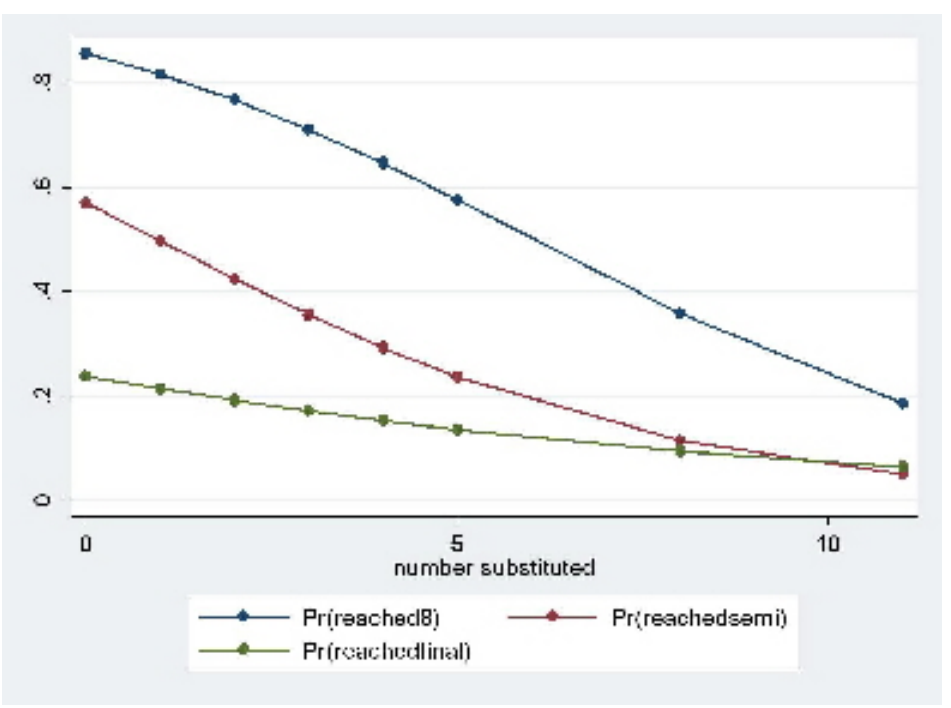

Fig 4: Success in Worldcup

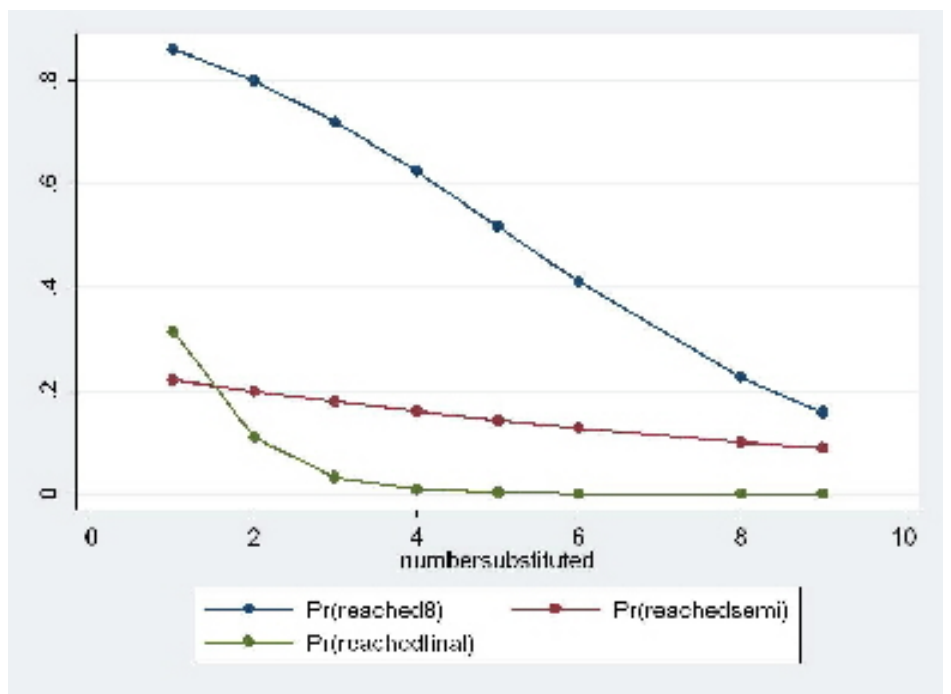

Fig 5: Success U20 worldcup 


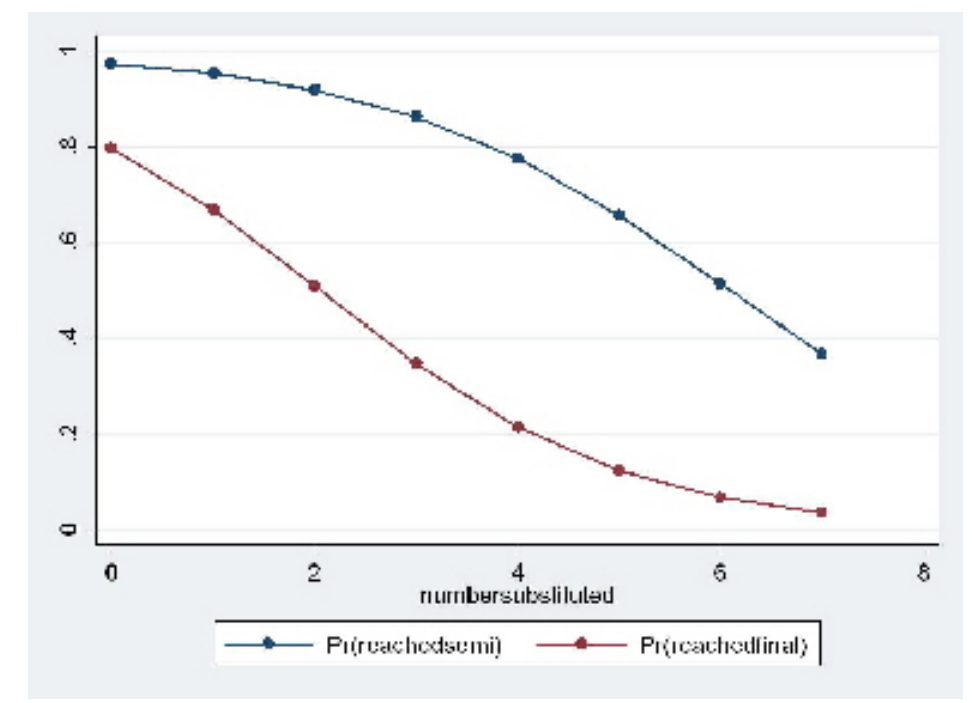

Fig 6: Success Olympic Tournament

Clearly substituting more players has a strong negative impact on the probability to win further games in the tournament. Why could this be the case ? Our hypothesis is that the reason for this effect is mainly psychological. One conjecture could be that upon substituting many players there is a higher chance to loose the last match of the tournament, which then could affect the confidence of the team in the following match. A first indication is to check whether the two are correlated. We do a Spearman test and find that for the worldcup there is negative correlation as expected ( $\rho=$ $-0.1960)$ but not significantly so $(p=0.3478)$. In the U20 worldcup there is esentially no correlation ( $\rho=0.0062, p=0.9771)$ as there isn't in the olympic tournament $(\rho=0.0096, p=0.7212)$. The weak correlations overall can suggest that the substitute players do well, but it could also be that coaches tend to substitute more if they judge the last game of the group to be "easy". Even though substitutions seem not substantially correlated with success in the last match of the group we still want to explore how the number of players substituted fares as an explanation of success compared to the fact that the last game in the group (and hence possibly confidence) was lost.

To dig deeper into this question, we ran logit regressions of the probability to reach the quarterfinal $(\operatorname{Pr}($ reach8) $)$, semifinal and final conditional on having reached the previous round as a function of the following variables: $n$ (the number of substitutions), a dummy $\delta_{L} \in\{0,1\}$ taking the value 1 if the last game was not won, a dummy $\delta_{1} \in\{0,1\}$ indicating whether the team finished first in the group as well as interaction terms. We present the results in the following regression tables 


\begin{tabular}{lllll}
$\operatorname{Pr}($ reach $)$ & $(1)$ & $(2)$ & $(3)$ & $(4)$ \\
\hline const. & $6.0829^{* *}$ & $6.0364^{* *}$ & $5.7831^{* *}$ & $5.9181^{* *}$ \\
& $(2.67)$ & $(2.62)$ & $(2.43)$ & $(2.57)$ \\
$n$ & $-0.7455^{* *}$ & $-0.7052^{* * *}$ & $-0.6324^{* *}$ & $-0.6773^{* *}$ \\
& $(0.35)$ & $(0.33)$ & $(0.29)$ & $(0.34)$ \\
$\delta_{L}$ & -0.94 & -1.1059 & & \\
& $(1.70)$ & $(1.98)$ & & $-3.2546^{*}$ \\
$\delta_{1}$ & $-3.5606^{*}$ & & & $(1.86)$ \\
& $(1.89)$ & & -0.4582 & -0.5158 \\
$\delta_{L} * n$ & & & $(0.54)$ & $(0.53)$ \\
& & & $-1.3690^{*}$ & \\
$\delta_{1} * n$ & & $-1.3874^{*}$ & $(0.77)$ & \\
& & $(0.78)$ & 0.6441 & 0.5806
\end{tabular}

Table 7 Logistic Regression, prob. to reach Worldcup quarterfinal,

$\left(\left(\operatorname{Pr}>\varkappa^{2}\right)<0.0001\right)$

As can be seen from Table 7 the number of substitutions in the third game has a clear negative effect on the probability to reach the quarterfinal, which is significant at the $5 \%$ level. Also the effect of the position of a team seems to matter, even though a coefficient of zero is within the $95 \%$ confidence interval. It may seem surprising that the fact whether a team ended up first or second in the group is not a better predictor of success. Remember, though that we are focusing uniquely on teams that are qualified after two games already and hence typically are strong teams anyway. Finally note that there is no significant effect of whether the last game was lost or not.

\begin{tabular}{lllll}
$\operatorname{Pr}($ reach 8$)$ & $(1)$ & $(2)$ & $(3)$ & $(4)$ \\
\hline const. & $2.2489^{* *}$ & $2.3669^{* *}$ & $2.2613^{* *}$ & $2.0903^{* *}$ \\
& $(1.14)$ & $(1.21)$ & $(1.12)$ & $(1.05)$ \\
$\delta_{4}$ & $-2.4635^{* *}$ & $-2.6102^{* *}$ & $-2.2613^{*}$ & $-2.0903^{*}$ \\
& $(1.19)$ & $(1.27)$ & $(1.33)$ & $(1.05)$ \\
$\delta_{L}$ & -0.3875 & -0.2821 & & \\
& $(0.72)$ & $(1.10)$ & & -2.1097 \\
$\delta_{1}$ & -1.9090 & & & $(1.71)$ \\
& $(0.28)$ & & & -1.0986 \\
$\delta_{L} * \delta_{4}$ & & & $(1.35)$ & $(1.35)$ \\
& & & $-1.0342^{*}$ & \\
$\delta_{1} * \delta_{4}$ & & -0.9652 & $(0.73)$ & \\
& & $(0.77)$ & 0.2695 & 0.2439
\end{tabular}

Table 8 Logistic Regression, prob. to reach U20 Worldc. quarterfinal $\left(\left(\operatorname{Pr}>\varkappa^{2}\right)<0.0006\right)$

In the U20 worldcup the picture looks similar. There is a clear negative effect of more substitutions in the third game, which is significant at the $5 \%$ level. Note, though that we have used the variable $\delta_{4}$ instead of $n$, which more than doubled the $R^{2}$ of our regression. In the U20 worldcup the fact of substituting more than 4 players seems crucial, but given this there seem to be no further effects 
on the number of players substituted. We also loose a lot of $\mathrm{R}^{2}$ if we eliminate the insignificant variables.

If we pool the data from the two worldcups and include a dummy for the U20 worldcup we find results which are not qualitatively much different. These regressions reveal (as do the tables 1-3) that the probability to pass on to the quarterfinal (for those qualified after two games) is higher in the senior worldcup than in the U20 worldcup. ${ }^{4}$.

\begin{tabular}{lllll}
$\operatorname{Pr}($ reach 8$)$ & $(1)$ & $(2)$ & $(3)$ & $(4)$ \\
\hline const. & $7.9775^{*}$ & $7.3054^{* *}$ & $6.3912^{* *}$ & $7.0079^{* *}$ \\
& $(4.19)$ & $(3.70)$ & $(3.27)$ & $(3.70)$ \\
$n$ & $-1.1836^{*}$ & $-1.0695^{* *}$ & $-0.9542^{*}$ & $-1.0572^{*}$ \\
& $(0.60)$ & $(0.49)$ & $(0.58)$ & $(0.64)$ \\
$\delta_{L}$ & -1.5361 & -1.4151 & & \\
& $(1.83)$ & $(1.76)$ & & $-4.5129^{*}$ \\
$\delta_{1}$ & $-4.0742^{*}$ & & & $(3.00)$ \\
& $(2.30)$ & & & -0.1660 \\
$\delta_{L} * n$ & & & $(0.29)$ & $(0.30)$ \\
& & & -2.3588 & \\
$\delta_{1} * n$ & & -2.1612 & -2.302 & \\
& & $(2.27)$ & $(2.47)$ & \\
\hline \hline$R^{2}$ & 0.4366 & 0.4903 & 0.4696 & 0.4169
\end{tabular}

Table 9 Logistic Regression, prob. to reach olympic semifinal

$$
\left(\left(\operatorname{Pr}>\varkappa^{2}\right)<0.0001\right)
$$

Also in the Olympic tournament there is a negative effect of substitutions on the probability of reaching the semifinal, which is mostly significant at $10 \%$. We cannot reject the hypothesis that both other coefficients are zero, but the $\mathrm{R}^{2}$ of the regression drops below 0.2 upon eliminating them. Finally for the regressions on semifinal and final in case of the worldcups and final in case of the olympic tournament none of the coefficients are significant. ${ }^{5}$

We can conclude that there is an effect of the number of substitutions which is neither (uniquely) due to the fact that upon making the substitution the first position in the group is lost (and hence a possibly more difficult opponent waiting in the next round) nor to the fact that the last game of the group phase and hence confidence is lost. Rather it seems that substituting many players leads to a loss of mental focus or overconfidence.

\section{Discussion}

What could be an explanation of our results ? Neglecting psychological factors, we would expect either that those teams that have qualified already after two games pass on to the quarterfinal with higher probability because they revealed to be the better teams or that the opposite is true because those teams that are already qualified have exerted more effort and hence are more tired when it comes to playing the round of last 16. Our evidence can reject the second hypothesis, but does not contradict the first.

With respect to the negative impact of substitutions we believe that our results are evidence of psychological mechanisms caused by the high number of substitutions which lead to failure in the Round of last 16 (quarterfinal).

\footnotetext{
${ }^{4}$ The regression table is available upon request.

${ }^{5}$ The regression tables are available upon request.
} 
It could also be argued that coaches substitute more players in the last game if many players were injured or received yellow cards in previous matches and that hence it is only natural to expect that these teams should fare worse. This explanation does not hold up, though. Across all substitutions less than $6 \%$ concerned players with yellow cards or injured players.

One might also be tempted to think that there are unobserved characteristics of the coaches of the teams which correlate both strongly with a tendency to substitute many players and a tendency to make bad line ups or other decisions which lead to a higher probability of loosing games. This explanation cannot hold up, though, since all the teams we investigate are highly succesful until the substitution decision is made.

Finally among possible psychological factors, the results have shown that we can probably rule out a loss of confidence as explanation for this phenomenon. Other possible explanations could be a loss of mental focus if the substitutions imply a too long break for the players subtituted or overconfidence building up more strongly in a longer match break. A factor reinforcing these effects could be that players are more certain that they will be in the line-up in the Round of Last 16, if they have been previously substituted in the third match. This certainty could also lead to a loss of mental focus or match tension.

\section{References}

[1] Apesteguia, J. and I. Palacios-Huert (2008), Psychological Pressure in Competitive Environments: Evidence from a Randomized Natural Experiment, UPF working paper 1116.

[2] Brown, T., J. van Raalte, B. Bewer, C. Winter and A. Cornelius (2002), World Cup Soccer Home Advantage, Journal of Sports Behavior, 25.

[3] Della Vigna, Stefano (2007), Psychology and Economics: Evidence from the Field, Journal of Economic Literature, in press.

[4] Duggan, M. and S. Levitt (2002), Winning isn't Everything: Corruption in Sumo Wrestling, American Economic Review 92(5), 1594-1605.

[5] Edwards, J. and D. Archambault (1989), The home field advantage. In J. H. Goldstein (Ed.), Sports,games, and play: Social and psychological viewpoints (2nd ed.,pp. 333-370). Hillsdale, NJ: Lawrence

[6] Heckman, James (2008), Schools, Skills and Synapses, IZA Discussion paper 3515. 